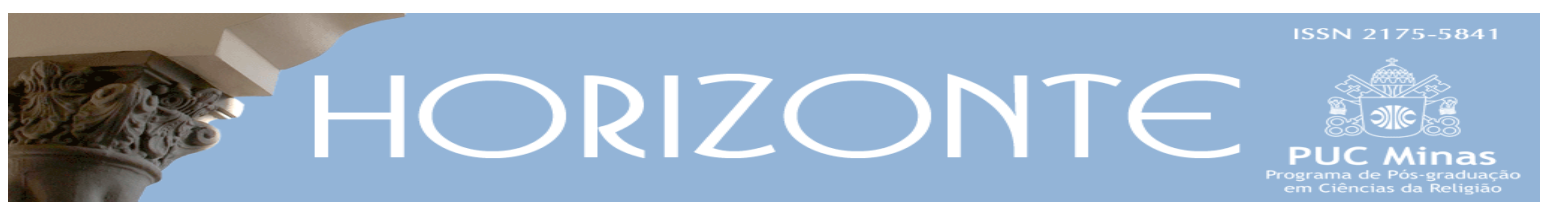

Dossiê: Teorias da religião - Artigo original (@) $(0)$

\title{
Teologia negra: a fenomenologia do damné como caminho de humanização
}

\author{
Black theology: the phenomenology of damné as a path of humanization
}

\author{
Cleusa Caldeira *
}

\begin{abstract}
Resumo
Com este texto busca-se contribuir com os Estudos da Religião a partir da reabilitação da tradição do pensamento negro crítico e, ao mesmo tempo, entabular um pensamento teológico antirracista e despatriarcalizado. Assume-se, pois, a crítica decolonial que coloca em relevo o racismo epistêmico e ontológico que segue invisibilizando e aniquilando uma porção considerável da humanidade. No marco do diálogo epistemológico Norte e Sul, segue-se a proposta de uma ontologia relacional da gratuidade propugnada pela teologia pós-moderna niilista latino-americana, para pensar o fim da violência intersubjetiva e a instauração da intersubjetividade, isto é, o estágio harmonioso do mútuo reconhecimento. Intui-se, entretanto, que não é possível pensar em ontologia relacional fora da fenomenologia dos damnés da terra (Fanon), isto é, sem a assunção da exterioridade da Modernidade. Sem considerar o colonialismo e a colonialidade como fraturas profundas na intersubjetividade parece difícil propugnar um futuro razoável para a humanidade e o planeta, pois seguiremos cúmplices da necropolítica e sua pulsão genocida que estrutura o capitalismo global (Mbembe). Deseja-se, assim, sinalizar um novo caminho para o pensamento teológico negro com ferramentas teóricas e conceituas atualizadas.
\end{abstract}

Palavras-chave: pensamento negro; teologia negra; pensamento decolonial; sujeitos damnés; ontologia relacional.

\begin{abstract}
This text seeks to contribute to the Studies of Religion from the rehabilitation of the tradition of critical black thought and, at the same time, to develop an anti-racist and de-territoralized theological thinking. It is assumed, then, the decolonial critique that emphasizes the epistemic and ontological racism that continues to invisibilize and annihilate a considerable portion of humanity. Within the framework of the North and South epistemological dialogue, the proposal of a relational ontology of gratuitousness advocated by postmodern Latin American nihilist theology follows, to think about the end of intersubjective violence and the establishment of intersubjectivity, that is, the harmonious stage of mutual recognition. However, it is not possible to think of relational ontology outside the phenomenology of the damnés of the earth (Fanon), that is, without the assumption of the exteriority of Modernity. Without considering colonialism and coloniality as deep fractures in intersubjectivity, it seems difficult to advocate a reasonable future for humanity and the planet, since we will continue to be accomplices of necropolitics and its genocidal drive that structures global capitalism (Mbembe). It is thus intended to signal a new path for black theological thinking with up-to-date theoretical and conceptual tools.
\end{abstract}

Keywords: black thought; black theology; decolonial thinking; Damnés subjects; relational ontology.

Artigo submetido em 16 de junho de 2019 e aprovado em 30 de agosto de 2019.

* Doutora em Teologia pela FAJE. Professora colaboradora da FAJE (PNPD/CAPES). Bolsista Capes. País de origem: Brasil. E-mail: cleucaldeira@gmail.com 


\section{Introdução}

O Brasil contém o segundo maior contingente de negros do mundo, perdendo apenas para a Nigéria. Os Estudos da Religião têm produzido importantes pesquisas ligadas ao pensamento negro e, sobretudo, à comunidade negra em diáspora, mais especificamente ligadas às religiões de matriz africana. Entretanto, a teologia ainda não conseguiu assumir a "condição negra" e o racismo como tarefa ingente e urgente. Essa constatação pode ser verificada tanto na ausência de uma disciplina de teologia negra nos cursos de (pós)graduação, como uma maior incidência junto à população negra brasileira, cuja lutas e resistências se encontram às margens do debate teológico. Isso aponta para a necessidade de o pensamento teológico assumir a crítica decolonial, para a produção de outras formas de construção do saber, que parta das margens do conhecimento e da história de dominação.

Foi exatamente essa relação dialógica entre movimentos negros emancipatórios e pensamento teológico que fez surgir a teologia negra propriamente dita, nos meados dos anos de 1966-1969, nos Estados Unidos, no contexto das lutas contra a segregação racial e pelos direitos civis da comunidade negra. A teologia negra surge, pois, da tentativa de compreender, por um lado, a identidade da comunidade negra, em sua maioria cristã, e, por outro lado, a compatibilidade entre ser negro e cristão, no seio de uma sociedade branca, cristã, patriarcal e racista. Fulcral para o nascimento da teologia negra é a afirmação da humanidade negra e a emancipação do racismo branco, sem os quais não pode haver autêntica libertação, tanto para os negros quanto para os brancos (CONE, 1986, p. 123).

Essa teologia torna-se uma autêntica teologia da libertação negra quando a comunidade negra se apropria do Evangelho - não como um dom dos seus opressores - mas como um ato de resistência que reconhece em Cristo a condição negra (CONE, 1986, p. 122). Para a teologia negra norte-americana, o conceito “pobre”, tão precioso à teologia da libertação, não dá conta da experiência de 
opressão negra, pois não considera o racismo que incide sobre os corpos negros em suas análises. Se a teologia da libertação mostrou seu limite em relação à construção histórica do negro e da raça, a teologia negra estadunidense, ao menos em seu início, limitou-se a pensar a libertação apenas para o povo negro norteamericano, visto que ela não considerava as diversas experiências de racismo que vivenciavam em outras partes do mundo. Diante do limite tanto da teologia negra norte-americana como da teologia da libertação, sujeitas e sujeitos teológicos negros gestaram um pensamento crítico a partir das margens, isto é, do Sul Global.

Em 1980, então, surge na América Latina a teologia afro-americana ou teologia da libertação negra como instância crítica à teologia da libertação, para que esta supere a libertação reduzida às questões político-sociais na assunção de um compromisso com rostos concretos que vivem a opressão cultural e étnica (PADILHA, 2003, p. 111). Isso significa assumir a discriminação racial como fator determinante para a situação do povo oprimido, fazendo surgir a teologia afroamericana como resposta teológica ao racismo que estrutura as relações intersubjetivas. A teologia afro-americana tonou-se, assim, uma ferramenta importante no despertar da consciência negra e da opressão que padece o povo negro na América Latina. Na intersecção de classe e racismo, ela buscou dar conta da condição negra sob a racionalidade eurocêntrica.

Entretanto, no que tange as pesquisas acadêmicas, percebe-se que, de maneira geral, o pensamento teológico negro no Brasil foca-se mais nas análises dos textos bíblicos e na história do povo negro. Isso fica evidente na produção intelectual das teólogas negras e dos teólogos negros, que se concentram suas publicações principalmente na revista Estudos Bíblicos e na Revista de Interpretação Bíblica Latino-americana (RIBLA). Há 30 anos, a revista Estudos Bíblicos (1988) publicou dois volumes dedicados à teologia negra. O primeiro, Eu ouvi o clamor do meu povo, foi uma crítica à Campanha da Fraternidade que teve o mesmo título como tema. O segundo volume, O negro e a Bíblia: um clamor de justiça, assim como o primeiro, se constitui em releituras de narrativas bíblicas que buscavam denunciar a opressão racial do povo negro. De igual modo, a Revista de 
Interpretação Bíblica Latino-americana tem sido uma excelente ferramenta para divulgar as pesquisas voltadas para o enegrecimento da teologia. Destaca-se o número 54, Raízes afro-asiáticas no mundo bíblico (REVISTA DE INTERPRETAÇÃO BÍBLICA LATINO-AMERICANA, 2006), que marca uma mudança paradigmática nas pesquisas bíblicas, com a redescoberta da influência dos povos africanos na constituição da tradição judaico-cristã. Nesta perspectiva, biblistas como o afro-americano Peter T. Nash e a afro-colombiana Maricel Mena López são referências importantes para os estudos bíblicos no Brasil. Essa mudança possibilita a Hermenêutica Negra Feminista reabilitar o protagonismo das mulheres negras no mundo bíblico (CALDEIRA, 2013, p. 1189-1210).

Além das pesquisas bíblicas, a teologia afro-americana no Brasil busca reescrever a história de sofrimento e resistência do povo negro, que seja capaz de suscitar a esperança em um mundo melhor. Antônio Aparecido da Silva (Pe. Toninho) é considerado um dos principais representantes do pensamento teológico negro no Brasil. Neste sentido, a obra coletiva 500 anos de invasão, 500 anos de resistência (ZWETSCH, 1992) é um marco importante, visto que nela se busca recontar a história de horror do racismo mesclada com a história de resistência do povo negro. Há, neste sentido, muitos textos que buscam reconstruir a história do povo negro no Brasil. Entretanto, constata-se um vazio no que tange a referências de produção intelectual de negras e negros de um pensamento teológico crítico sistemático contemporâneo, isto é, não há uma teologia fundamental negra brasileira com ferramentas teóricas e conceituas atualizadas. Ainda a maior referência é a "teologia negra" (1986), do teólogo norte-americano James Cone.

Neste sentido, com este texto deseja-se sinalizar um caminho urgente e necessário para a teologia negra, que possa pensar na questão da intersubjetividade como mútuo reconhecimento na gratuidade. Isso implica em assumir a crítica decolonial e, sobretudo, a "universalização da condição negra", como vem afirmando Achille Mbembe (2018). Para isso, no marco do diálogo epistemológico Norte e Sul, uma teologia negra fundamental deverá seguir a proposta de uma ontologia relacional da gratuidade propugnada pela teologia pós-moderna niilista 
latino-americana, para pensar o fim da violência intersubjetiva e a instauração da intersubjetividade, isto é, o estágio harmonioso do mútuo reconhecimento para além da dialética hegeliana, sem o "esquecimento da colonialidade" (MALDONADO-TORRES, 2008, p. 73).

\section{Teologia negra em perspectiva decolonial}

A teologia negra em perspectiva decolonial implica em apresentar o pensamento e a ação antirracista, que sejam capazes de superar o racismo contemporâneo; visto que o pensamento e a ação antirracista clássicos se encontram em crise e necessitam igualmente renovar suas ferramentas teóricas e conceituais (BURASCHI; AGUILAR-IDÁÑEZ, 2017, p. 171). Para isso, faz-se necessário reabilitar a tradição do pensamento crítico negro, uma tradição invisibilizada pela academia latino-americana. Essa invisibilização da tradição crítica do pensamento negro faz com que muitas ideias trabalhadas pelos negros marxistas ${ }^{1}$ sejam tradadas como novidades. Entretanto, conforme aponta Ramón Grosfoguel (2018, p. 11), a ocultação das origens negras das teorias críticas - tais como a teoria "sistema-mundo", a "colonialidade do poder" e o "colonialismo interno" - acaba reproduzindo o racismo epistêmico, que segue afirmando a inferioridade do pensamento negro e a superioridade do pensamento branco.

Diante desta "injustiça epistêmica" com o pensamento crítico negro, propõese entabular um pensamento teológico negro na interlocução com o pensamento crítico negro. Nisto não há nada de novo, visto que o próprio pensamento decolonial recupera a genealogia do pensamento negro como sendo avant la lettre do pensamento decolonial. A novidade está em articular um pensamento teológico na interlocução com o pensamento crítico negro.

Talvez, esse tenha sido o grande limite da teologia negra, como bem assinalou o filósofo afro-americano Corner West em seu capítulo "teologia negra e pensamento marxista" na clássica obra Teologia negra: "os teólogos negros não se

\footnotetext{
${ }^{1}$ São considerados negros marxistas: Aimé Césaire, W.E. R. Du Bois, Cedric J. Robinson, Frantz Fanon e outros.
} 
servem de uma teoria social que relaciona a opressão dos negros à composição geral dos sistemas americanos de produção, de política externa, de acordo político, e de práticas culturais" (WEST, 1986, p. 456-475). Uma consequência desta ausência de interlocução com as teorias sociais resulta na inexistência de uma crítica mais contundente pela teologia negra ao conceito raça e do negro, bem como, sua intrínseca relação com a estrutura do capitalismo global e, portanto, com sua pulsão genocida.

Por outro lado, nisto consiste a inovação da Teologia da Libertação ao se servir de alguns aspectos do marxismo para falar do Terceiro Mundo, que lhe possibilitou, a seu modo e a seu tempo, criticar a estrutura injusta que segue aniquilando os pobres da terra. Agora sob o marco do pensamento decolonial, com outras teorias críticas, como a do sistema/mundo moderno/colonial, se pode ampliar a crítica realizada pela Teologia da Libertação, pois não é possível compreender o chamado Terceiro Mundo sem o Primeiro Mundo, isto é, na construção história do binômio centro-periferia como fundamentais para a implementação e a perpetuação do capitalismo global. Com isso, o pensamento decolonial vem colocando em relevo o racismo epistêmico e ontológico que estrutura o pensamento e a ação no mundo ocidental. Ao revelar o "epistemicídio" da razão moderna (SPIVAK, 2003, p. 297-364), o pensamento decolonial interpela os distintos saberes à uma revisão epistemológica, partindo do fato histórico da colonização e da colonialidade como determinante epistemológico.

\subsection{Colonialismo como a grande fratura na intersubjetividade}

Em seu livro "Discurso sobre o colonialismo", Aimé Césaire (2006) pergunta: 'o que é a colonização?'. De fato, parece difícil uma aproximação ao real sem compreender a ruptura epistemológica que significou o colonialismo enquanto projeto civilizatório que se instalou como uma realidade imutável. Antes de responder a essa questão, Césaire explicita primeiro o que não é a colonização, isto é, "nem evangelização, nem empresa filantrópica, nem vontade de recuar as 
fronteiras da ignorância, da doença, da tirania, nem propagação de Deus, nem extensão do Direito" (CÉSAIRE, 2006, p. 14). Pelo contrário, a colonização produz uma degeneração no humano, tanto no colonizador quanto no colonizado; visto que a "colonização se esmera em descivilizar o colonizador, em embrutece-lo, na verdadeira acepção da palavra, em degradá-lo, em despertá-lo para os instintos ocultos, para a cobiça, para o ódio racial, para o relativismo moral"(CÉSAIRE, 2006, p. 17).

Césaire, assim, nega qualquer valor humano na colonização, pois nela o "colonizador, para se dar boa consciência se habitua a ver no outro o animal, se exercita a tratá-lo como animal, tende objetivamente a transformar-se, ele próprio, em animal" (CÉSAIRE, 2006, p. 23-24). Esse sistema desumano nunca deixou de operar, nem mesmo com o advento do pós-colonial.

“Quando foi o pós-colonial?”, pergunta Stuart Hall (2003, p. 101). Longe de designar apenas o "fechamento final de um período histórico, como se o colonialismo e seus efeitos estivessem definitivamente terminado" (HALL, 2003, p. 102), o pós-colonial emerge enquanto uma postura crítica em vista da superação das grandes narrativas imperiais do passado. Trata-se de uma resposta a uma necessidade genuína de superar a crise de compreensão produzida pela incapacidade das velhas categorias de explicar o mundo (HALL, 2003, p. 123-124). Com efeito, o pós-colonial se refere a uma releitura da colonização enquanto um "processo global essencialmente transnacional e transcultural", que "produz uma reescrita descentrada, diaspórica ou 'global' das grandes narrativas imperiais do passado, centradas na nação (HALL, 2003, p. 109). Historicamente falando, o conceito pós-colonialismo surgiu no período pós-guerra com intelectuais do "Terceiro Mundo" radicados no mundo inglês e norte-americano (BERNARDINOCOSTA; GROSFOGUEL, 2016, p. 15). 
Do pós-colonial há muitas derivações, como o pensamento decolonial ligado ao Grupo Modernidade/Colonialidade ${ }^{2}$, que busca coloca em relevo o vínculo intrínseco entre colonialidade e modernidade. Isso significa que a modernidade não pode ser interpretada como um fenômeno do Iluminismo, antes, ela nasce enquanto projeto político-econômico de expansão colonial levado a cabo pela Espanha e Portugal, no fim do século XV e XVI. De maneira, que o capitalismo, a modernidade e a colonialidade estão indissoluvelmente conectadas, como se fosses "três membros" da equação do sistema-mundo (MIGNOLO, 2007, p. 26).

O pensamento decolonial concebe a colonialidade como um fenômeno muito mais complexo e duradouro que o colonialismo. A colonialidade vai muito além do significado convencional interpretado como um sistema de controle políticoeconômico e jurídico de certa população, a colônia, por uma nação estrangeira, a metrópoles.

O pensamento decolonial, ao considerar a Modernidade e a Colonialidade como autoconstitutivas, tece uma crítica à Modernidade/Colonialidade de modo a superar essa constituição de domínio. A essa crítica dá-se o nome de giro decolonial, que consiste em desvelar esse domínio colonizante presentes nos modos de produção de conhecimento (colonialidade do saber), na maneira como opera o etnocentrismo europeu do ponto de vista econômico e sociocultural (colonialidade do poder) e na forma como os modos de ser, que prioriza a racionalidade ocidental, oprimem outros modos de ser igualmente validos (colonialidade do ser/ da subjetividade) e o controle e a exploração do meio ambiente (colonialidade da natureza).

A decolonialidade se refere à necessidade de uma autêntica decolonização e superação da falácia da primeira decolonização, que foi reduzida à superação da independência jurídico-política das periferias. Longe de reduzir a decolonialidade à um projeto acadêmico, trata-se de uma prática de oposição e intervenção que

\footnotetext{
${ }^{2}$ Ao grupo modernidade/colonialidade integram autores como Enrique Dussel, Aníbal Quijano, Walter Mignolo, Ramón Grosfoguel, Nelson Maldonado-Torres, Catherine Walsh e outros.
} 
irrompeu concomitante ao primeiro sujeito colonial produzido pelo sistema mundo moderno/colonial, em 1492 (BERNARDINO-COSTA; GROSFOGUEL, 2016, p. 17). Nesse sentido, Walter Mignolo afirma que a ideia de "colonialidade" já estava implícita em toda a tradição do pensamento negro, que acaba sendo a base de uma nova genealogia do pensamento decolonial a partir do conceito de "colonialidade do poder" cunhado por Aníbal Quijano (MIGNOLO, 2007, p. 26-28). A decolonialidade busca, pois, superar a pretensão de universalidade europeia e, ao mesmo tempo, reabilitar as outras formas de produção de conhecimento e vida além do eurocentrismo.

\subsection{Decolonização da teologia}

Postular a decolonização da teologia deve-se partir da constatação do "papel histórico do cristianismo como arma colonial de controle religioso e dominação desejada" (DUGGAN, 2013, p. 12). E coube ao pensamento decolonial explicitar o papel fundamental da teologia cristã em fornecer o fundamento para a racialização da humanidade. De maneira especial, isso aconteceu a partir do debate sobre o "Direitos das gentes", com o frei Bartolomeu de Las Casas, Gines de Sepúlveda e o frei Francisco de Vitoria, ao questionarem se os indígenas eram seres humanos com pleno direitos teológicos e jurídicos. Essa discussão transitou do reconhecimento de sua possível humanidade à afirmação de sua animalidade ou barbárie. Aos ameríndios se deu, ao final, o reconhecimento de sua humanidade, legitimando assim a agência evangelizadora do Novo Mundo; visto que seres considerados bestas não poderiam ser evangelizados. Contudo, esse reconhecimento da humanidade dos ameríndios incrementou a demanda pelos escravos africanos, sob o status de não humanos e, por isso, passíveis de serem escravizados. Assim, para Maldonado-Torres (2007, p. 145), esse "ceticismo misantrópico", isto é, a suspeita teológica acerca da humanidade do outro, foi crucial para desenvolver a colonialidade do ser e do saber, juntamente com o racismo e a exclusão ontológica (MALDONADO-TORRES, 2007, p. 145). Desta forma, a decolonização do cristianismo aparece como um imperativo ético e epistêmico. 
Enrique Dussel, em seu artigo "Descolonização epistemológica da teologia" (DUSSEL, 2013, p. 19-30), afirma que uma teologia decolonizada implica na reabilitação do messianismo originário. Ora, a necessidade de recuperar o messianismo originário revela que houve, ao menos, dois momentos específicos na história em que este se distanciou de sua Fonte e Horizonte, que é Deus em linguagem monoteísta.

O primeiro se deu na integração do cristianismo ao Império romano com Constantino, que fez surgir à cristandade, com sua fé no Cristo Pantocrator, o Todo-poderoso, o Uno. A este movimento, Dussel (2013, p. 20-21) chama de "inversão do messianismo para o cristianismo triunfante [...]. Os messiânicos [...] deixam de ser críticos do império para serem seus decididos partidários, seus membros, e com o tempo seus defensores" (DUSSEL, 2013, p. 20-21). Estruturouse, assim, a nova cultura como fruto da síntese da cultura greco-romana e cristã, inicia-se a era da cristandade, mas ainda marginal em relação ao restante do mundo.

O segundo momento de distanciamento do cristianismo de sua essência, foi a partir de 1492, data simbólica do nascimento da modernidade e encobrimento do outro (DUSSEL, 1994, p. 7), sob o projeto expansionista da Europa, quando a cristandade assume uma face ainda mais "nefasta". Surge, o cristianismo monocultural que se constituirá na "quinta essência", isto, é, na "coluna vertebral" do eurocentrismo (DUSSEL, 2013, p. 28). Emerge, assim, a cristandade imperial e colonial, que "crucificará indígenas em nome do Crucificado" (DUSSEL, 2013, p. 23). Não apenas crucificará indígenas, mas legitimará a redução do outro à inumanidade, em vista de sua escravização e instauração do sistema/mundo moderno/colonial.

A decolonização da teologia, por sua vez, engendra-se quando novos sujeitos teológicos assumem essa visão de mundo do sistema/mundo moderno/colonial e se situam em um novo espaço como locus enunciativo e hermenêutico. E, nesse lugar preciso, refaz toda a teologia. Neste horizonte, uma teologia decolonizada 
implica na superação da geopolítica de Estado de conhecimento eurocentralizado e na assunção de uma geopolítica de Estado de alteridades negadas, de outras sabedorias, de outras espiritualidades, de políticas outras, de economias outras, etc. Isso implica no advento da "transmodernidade" enquanto projeto epistemológico alternativo à modernidade eurocêntrica.

[O] conceito estrito de "transmoderno" indica essa novidade radical que significa o surgimento - como se a partir do nada - da exterioridade, da alteridade, do sempre distinto, de culturas universais em desenvolvimento, que assumem os desafios da Modernidade e, até mesmo, da pós-modernidade euro-americana, mas que respondem a partir do outro lugar [...], do ponto de sua própria experiência cultural, diferente da euro-americana, portanto capaz de responder com soluções completamente impossíveis para a cultura moderna única. (DUSSEL, 2016, p. 63).

A transmodernidade pressupõe a pluriversalidade, resultado de um autêntico diálogo intercultural. Ora, esse diálogo intercultural necessita, por sua vez, ser transversal: um diálogo que se dá a partir da periferia para a periferia; um diálogo sul-sul. Enfim, a "transmodernidade é um projeto de libertação das vítimas da Modernidade, e o desenvolvimento de suas potencialidades alternativas, a 'outra-cara' oculta e negada" (DUSSEL, 2007). No horizonte de uma transmodernidade, afirma Dussel, somente uma "trans-teologia" poderá dizer sua palavra, assumindo sua contextualidade e vozes outrora silenciadas.

\begin{abstract}
Na idade Transmoderna que se aproxima (para além da Modernidade e do capitalismo) será necessária igualmente uma trans-teologia para além da teologia da cristandade latino-germânica, eurocêntrica e metropolitana, que ignorou o mundo colonial, e em especial as cristandades coloniais [...] que devem superar a colonialidade e a modernidade capitalista, invertendo a cristandade para retornar a um cristianismo messiânico profundamente renovado. (DUSSEL, 2013, p. 29-30).
\end{abstract}

Isso significa que a teologia já não poderá pretender dizer a última palavra como um novo universal imperial, antes se apresenta como um saber localizado e inacabado, visto que toda teologia é contextualizada. Ela deve apresentar-se como um convite ao diálogo, acolhendo e reconhecendo a alteridade e buscando formas de escutar os distintos gritos daquelas alteridades outrora silenciadas e negadas. 
Ora, a reabilitação do messianismo originário, sob o marco fenomenológico e desconstrucionista, denota o movimento de volta à coisa mesma da fé cristã. E $a$ coisa mesma da fé cristã, por sua vez, designa o perdão e o nascimento da identidade relacional. Sob o marco da racionalidade pós-moderna, o teólogo mexicano Carlos Mendoza-Álvarez inseriu o cristianismo hegemônico em sua própria desconstrução como um imperativo ético para conduzir à reabilitação do messianismo originário. Desconstruído o cristianismo de sua pretensão de totalidade, no marco fenomenológico, mimético e desconstrucionista a reabilitação do messianismo originário acontece sob o signo da temporalidade messiânica e kariológica, isto é, uma nova ordem de existência ontologicamente reconciliada inaugurada pelo Messias Jesus.

O messianismo interpretado numa perspectiva niilista assume, pois, o rosto de uma existência vivida até o extremo de si mesmo, como uma subjetividade afetada pela presença da "vítima perdoadora", isto é, a densa presença do Cristo, que vive o desejo como pura doação (CALDEIRA, 2018a, p. 313-319) . Trata-se de uma subjetividade que vive a temporalidade redimida de sua violência fraticida e sororicida. Sendo, pois, o messianismo uma ordem de existência vivida sob a gratuidade, a universalidade da mensagem de Jesus de Nazaré deve ser vivida por uma subjetividade que superou o ódio e o ressentimento, vivendo como uma subjetividade doadora (CALDEIRA, 2019, p. 1-25).

\section{Fenomenologia da subjetividade como lugar teológico}

A teologia pós-moderna niilista latino-americana desenvolvida por Carlos Mendoza-Álvarez, enquanto instância crítica à razão moderna, afirmou a impossibilidade de falar de Deus e do humano fora do marco da fenomenologia, visto que a experiência de devir humano se encontra intrinsecamente relacionada com o devir divino no mundo. Para dar conta de dizer, pois, a relação humanodivino em termos de comunicação plenamente realizada (MENDOZA-ÁLVAREZ, 
2010, p. 242)3, assume-se a descrição fenomenológica da subjetividade vulnerável como a principal interlocutora de Deus. Inserido na crítica niilista, inserido em sua própria desconstrução o cristianismo se abre à reabilitação de sua experiência fundacional pascal de Cristo, que do ponto de vista antropológico e fenomenológico assume o rosto da superação do ódio e o nascimento de uma identidade relacional marcada pela gratuidade amorosa (CALDEIRA, 2018b, p. 1270-1299).

Com isso, torna-se possível pensar a concreção histórica da redenção divina que acontece concomintante aos processos de subjetivação dos justos e das vítimas da história violenta da humanidade, quando elas alcançam o estágio mais elevado da subjetividade, isto é, a sua significação messiânica. Esse estágio da subjetividade escatológica advém quando se faz a passagem do ódio e do ressentimento ao perdão recebido e oferecido gratuitamente.

Para essa teologia niilista latino-americana, o messianismo emerge como um modo de ser-no-mundo para além da essência. Nesse horizonte, o messianismo não é outra coisa que a existência que vive a temporalidade messiânica e kairológica, na qual a redenção chega como "fagulhas" no coração da história violenta da humanidade, que se debate entre rivalidade e doação. A redenção chega, portanto, por meio dos gestos de extrema gratuidade das vítimas da história, que superando o ódio e o ressentimento abrem passagem para a instauração da intersubjetividade enquanto estágio harmonioso do mútuo reconhecimento para além da dialética hegeliana.

Para dar conta de dizer a experiência humano-divina, a teologia latinoamericana pós-moderna defende que somente por meio de uma ontologia relacional da gratuidade se poderá conjugar a livre iniciativa divina na oferenda do dom e a liberdade humana em sua recepção. Evidentemente, a proposta de uma ontologia relacional indica uma ruptura epistemológica em relação à ontologia da

\footnotetext{
3 “La comunicação plenamente realizada passa, assim, pela mediação existencial da doação enquanto renúncia de si mesmo totalitário, para colocar-se na lógica da subversão exposta por Emmanuel Levinas, mas por meio da instauração de relações sociais diferentes daquelas de possessão e de objetivação do real, típica da razão instrumental." (MENDOZA-ÁLVAREZ, 2010, p. 242).
} 
substância, cuja característica fundamental é a substância, e não a relação (KNAUER, 2012, p. 19-41).

Nesta perspectiva latino-americana pós-moderna, a resolução do conflituoso espaço público passa, portanto, por uma ontologia relacional e da gratuidade. Ora, eis o núcleo de uma problemática pouco trabalhada no pensamento teológico negro, isto é, a possibilidade de instauração da intersubjetividade enquanto estágio harmonioso do mútuo reconhecimento, por meio da superação do ódio e do ressentimento. Com efeito, a questão do perdão, do ressentimento e da reconciliação são pontos nevrálgicos da teologia negra, como bem tematizou o teólogo norte-americano James Cone (1985, p. 244-265).

\subsection{Fenomenologia a subjetividade vulnerável (pós)moderna}

A questão a superação do ódio e do ressentimento vem sendo tematizado a partir da reconstituição fenomenológica da subjetividade vulnerável pós-moderna. Para compreender essa acepção filosófica da subjetividade vulnerável pós-moderna é imprescindível um olhar retrospectivo e prospectivo da fenomenologia da subjetividade moderna. Um olhar retrospectivo dessa fenomenologia da subjetividade moderna constata-se a insuficiência do sujeito cartesiano e da subjetividade husserliana para dar conta da relacionalidade constitutiva de todo existente e sua abertura à alteridade. Com a subjetividade moderna chega a abertura da subjetividade à exterioridade, tanto com a vertente do pensamento niilista como aquele que confere primazia à alteridade na relação com o sujeito, com Heidegger e Levinas.

Ora, neste olhar retrospectivo acerca da constituição da subjetividade, percebe-se, pois, que nas análises da subjetividade na modernidade tardia, de Levinas, passando por Ricoeur, à Girard, o estágio da intersubjetividade como horizonte último da realização da identidade sempre aparece como utopia. "Um horizonte que parece estar sempre diferido na história e que, no entanto, é aquele que abre possibilidades de futuro na medida em que é percebido e imaginado pelos 
justos da história que sustentam assim uma possibilidade de existência para a humanidade inteira" (MENDOZA-ÁlVAREZ, 2007b, p. 15-52). Nessa reconstituição fenomenológica da subjetividade na modernidade tardia, tem-se o acesso à passagem da simples ideia de Deus à designação de Deus em função do horizonte hermenêutico e ético, com Ricoeur e Levinas. Ambas confluem na fenomenologia da subjetividade exposta como condição de possibilidade do encontro intersubjetivo. Nesse marco referencial, Carlos Mendoza-Álvarez, em sua obra Deus liberans, afirma que a "experiência do advento do sujeito é também um vestígio da transcendência de Deus inscrita no coração da subjetividade" (MENDOZA-ÁLVAREZ, 1996, p. 13).

Sob um olhar prospectivo, sob o pathos pós-moderno, se prossegue interpretando esse "rastro da transcendência" inscrita na imanência como escuta da presença do "Deus absconditus" na história conflitiva da humanidade. Nesse horizonte, segue-se no desenvolvimento de uma ontologia relacional como única maneira de justificar a relacionalidade constitutiva da subjetividade e da comunhão humano-divino como sentido último da criação (MENDOZA-ÁLVAREZ, 2011, p. 199-212). Essa constatação tornou-se possível porque a racionalidade niilista ultrapassou a ontoteologia e suas pretensões de absoluto. Heidegger foi crucial para esse ultrapassamento com sua fenomenologia da "subjetividade radical"; foi ele o mediador da transição da vontade de poder à vulnerabilidade. A subjetividade vulnerável, portanto, denota outra maneira de ser-no-mundo, inacabado, sempre em devir. A pós-modernidade, como pensamento crítico vigilante, assumirá como pathos da subjetividade a aguda consciência de sua vulnerabilidade, expressa na ideia de "sujeito vulnerável" 4 que permitirá descrever a constituição da subjetividade vulnerável pós-moderna.

Importa ressaltar que a hermenêutica da subjetividade vulnerável está enlaçada ao colapso do sujeito moderno. Depois desse colapso e dos seus sonhos de onipotência infantil, tornou-se possível uma nova hermenêutica do sujeito. Não

\footnotetext{
${ }^{4}$ Gianni Vattimo (1985) é a maior referência na ideia do "sujeito débil".
} 
uma hermenêutica da morte do sujeito, mas sim do colapso do ego moderno. Será esse colapso que viabilizará falar da subjetividade vulnerável como ponto de partida do conhecimento, de práxis de liberdade e de libertação e, portanto, abrir espaço para a superação do ego moderno. Não se trata apenas de denunciar a epopeia do ego e seus naufrágios, antes se busca descobrir - em plena comunhão com a tradição latino-americana em sua opção preferencial pelos pobres - a "potência dos pobres e excluídos", como defende o movimento antissistêmico pósmoderno (MENDOZA-ÁLVAREZ, 2013, p. 133).

Assim, no meio dos escombros da modernidade e da cristandade emerge o "sujeito vulnerável", por meio de quem se evidencia o esgotamento da racionalidade técnico-científica. Esta nova subjetividade, marcada pela aguda consciência da finitude, da culpabilidade e da possibilidade de redenção que chega pela alteridade amorosa, torna-se o novo locus theologicus. Em sua gênese:

A partir da assunção da própria vulnerabilidade, o sujeito débil começa a mostrar outro rosto para além da aparência anódina que o etiquetava em uma primeira impressão. Assim começa a gênesis de uma presença a si mesmo de caráter proativo, marcada pela tomada de distância frente aos sistemas de totalidade e sua influência nos mecanismos da própria subjetividade. (MENDOZA-ÁLVAREZ, 2010, p. 171-172).

Assim, o "sujeito vulnerável" desdobrará suas potências de experiência segundo a dinâmica de existência vivida nos limites de si mesmo. Com efeito, descobre "na fraqueza os vestígios de uma realidade outra por construir com a consciência aguda e sempre vigilante diante do provisório". De fato, o "sujeito vulnerável" em sua existência agônica constitui-se na única possibilidade de futuro para a humanidade, em tempos de colapso da modernidade e, consequentemente, do cristianismo enquanto matriz do Ocidente.

Esse "sujeito vulnerável”, em sua acepção histórica, encarna-se nos justos e nas vítimas da história de dominação que, a partir de suas potências de experiência desconstruídas de todo afã de onipotência, engendra uma mudança de mundo. 
São precisamente eles, os justos da história, que nos sustentam na consciência agônica vivida como experiência de viver até o último suspiro. Uma existência niilista na medida em que é vivida nos limites de si mesmo. Uma existência vivida como tal por um sujeito fraco porque se confrontou por sua própria experiência a uma vida que nunca deixa de enfrentar a morte. (MENDOZA-ÁLVAREZ, 2010, p. 224, grifo do autor).

Há, portanto, um significado ético-político da existência do "sujeito vulnerável". Longe de permanecer inerte diante dos excessos da racionalidade instrumental em sua lógica totalitária e do colapso do sujeito moderno, assume a vulnerabilidade como única possibilidade de existência histórica. Em outras palavras, o "sujeito vulnerável" assume a sua exclusão como lugar político, aprendendo a viver como "marginal no centro" dos debates públicos, na busca pelo reconhecimento dos direitos das minorias em meio aos sistemas de totalidades (MENDOZA-ÁLVAREZ, 2010, p. 190). Uma forte característica, pois, do "sujeito vulnerável" é o desencanto em relação aos metarrelatos de totalidade.

Ora, será com o filósofo Jean-Luc Nancy que a subjetividade vulnerável pósmoderna alcançará o estágio mais radical de abertura extrema a tudo o que existe5. Ele acrescenta à diferença niilista a perspectiva "mística" que está relacionada à experiência iconoclasta de Deus e, com isso, busca salvaguardar a condição apofática do discurso, da prática, do desejo e das ações. Com Nancy, o cristianismo será chamado à sua vocação kenótica como perpétuo ultrapassamento da religião e de todo sistema totalitário, isto é, para ser pertinente no atual contexto o cristianismo deverá assumir a sua própria desconstrução.

Seguindo pela via fenomenológica em direção à subjetividade vulnerável capax Dei, isto é, a subjetividade exposta e capacitada para o divino, se reconhece que não basta à subjetividade o desencanto característico do "sujeito vulnerável”; já não é possível uma hermenêutica teologal e teológica da subjetividade vulnerável

\footnotetext{
${ }^{5}$ As duas obras principais de Jean-Luc Nancy são: La déclosion e L'adoration; respectivamente, Nancy $(2005 ; 2010)$.
} 
fora da assunção do colapso da subjetividade em estado de "declosión" 6, que a habilite a adentrar no umbral escatológico do real (MENDOZA-ÁLVAREZ, 2007a, p. 41-55). Isso significa a possibilidade de ensaiar um discurso sobre Deus na pósmodernidade, a partir da realidade teologal da abertura e da indigência da subjetividade "declosionada”.

Nesse estágio, a subjetividade "declosionada” ficará radicalmente aberta, expectante, vigilante e em doação. Ora, essa subjetividade “declosionada” permite pensar na mudança de temporalidade que implica essa abertura, cavidade, ferida e indigência mesma da subjetividade aberta (MENDOZA-ÁLVAREZ, 2015a, p. 66). A subjetividade no estágio da "adoração niilista" é uma subjetividade fronteiriça, que possibilita acessar o "vazio criador", isto é: na fronteira do dizer, do pensar e do sentir está o vazio que se apresenta como fonte e destino de toda subjetividade em doação (MENDOZA-ÁLVAREZ, 2015a, p. 70-71). Desta forma, se delineia o pathos da subjetividade pós-moderna: “desencantada” e "desconstruída”. Cabe ressaltar que na declosión não predomina apenas o aspecto do desencanto típico do "sujeito vulnerável”, mas a subjetividade "declosionada" fica habilitada a permanecer “aberta, expectante, vigilante e doadora própria da adoração" (MENDOZAÁLVAREZ, 2015a, p. 72). Ao fim e ao cabo, designação da existência em estado de doação.

Para muitos analistas dos meandros da subjetividade, tais como René Girard e Jean-Luc Marion, esse estágio da doação parece impossível de se alcançar. Diferente desses, a teologia pós-moderna niilista compreende que esta questão permanece aberta à possibilidade da ontologia relacional da gratuidade (MENDOZA-ÁLVAREZ, 2015a, p. 72). A existência niilista - enquanto subjetividade "desencantada" e "declosionada" - vislumbra o resplendor da luz

\footnotetext{
${ }^{6}$ Carlos Mendoza-Álvarez esclarece que a Declosión é o processo de desconstrução do cristianismo como origem do Ocidente enquanto narrativa niilista da kénosis que funda o Ocidente. Um abaixamento divino que acontece desde a criação do universo e se consuma na encarnação do Logos divino. De forma que somente num a-teísmo será possível pensar este estágio atual da razão ocidental, visto que o despojo divino implica a renúncia da razão ao poder de toda representação, rito e símbolo que tenha por pretensão esgotar a "origem sem origem", que é Deus em linguagem monoteísta. A declosión, pois, é um neologismo cunhado por Jean-Luc Nancy para postular teoricamente o niilismo próprio da razão pós-moderna (MENDOZA-ÁLVAREZ, 2015a, p. 469). Para uma aproximação da desconstrução do cristianismo, ver Caldeira (2018b).
} 
obscura do "fundo sem fundo" do Mistério amoroso do Real. Entretanto, essa subjetividade ainda é insuficiente para justificar a instauração do mútuo reconhecimento a partir da assimetria do dom; portanto, a esta subjetividade lançada no devir da história e expectante no contínuo ato do "dizer", necessita-se integrar o estágio da "difícil doação".

Esse estágio da doação amorosa aparecerá como o início dos tempos messiânicos e da escatologia como temporalidade redimida, visto que o teólogo mexicano a interpretará a partir da proposição do pensamento antissistêmico, partindo das potências dos pobres e excluídos. Nisto se constitui a proposta de uma ontologia relacional, que seja capaz de justificar a impossível doação através dos gestos de extrema gratuidade dos pobres e das vítimas da história. Uma experiência, com efeito, que não se move sob a lógica da reciprocidade, visto que esta sempre conduz à violência e à exclusão; tampouco se fecunda no eterno retorno do ressentimento experimentado no presente e projetado à vida eterna. Antes, esse estágio da subjetividade como doação advém da experiência dos gestos gratuitos e inesperados dos invisibilizados pelos sistemas de totalidade e de onipotência (MENDOZA-ÁLVAREZ, 2015a, p. 73-74).

Por meio dos gestos de extrema gratuidade realizados pelos justos da história, pode-se perceber essa experiência da subjetividade exposta que habita a sua exclusão na assimetria do amor. Na ontologia relacional da gratuidade, esse gesto de extrema doação aparece como potência salvífica de toda humanidade e do planeta. De modo que a esperança possível para toda a humanidade passa pela entrega desmedida e assimétrica dos justos e inocentes da história. Vale recordar que os justos e os inocentes são "aqueles que, em meio de tanta mentira, vivem de maneira cotidiana sua vida como doação, seja por meio da prática do amor sem condições, seja inclusive pela oferenda misteriosa de sua vida pelos demais" (MENDOZA-ÁlVAREZ, 2010, p. 20). Cabe recordar que se trata de uma experiência anônima, experimentada por algumas pessoas desde a fundação do mundo, cujo protótipo será, para a antropologia e a teologia, o justo Abel. 
A pessoa em relação seria pura abstração se se ficasse somente na mútua interação dos pronomes [...]. O rosto desfigurado do outro, a ausência lacerante de quem foi aniquilado, e o clamor dos inocentes que são injustiçados por qualquer sistema de totalidade, são transfigurados pela vida entregada dos justos da história. Tal profundidade existencial é o que dá carne e sangue ao rosto do outro. Por isso é preciso incluir na ontologia relacional o clamor do sangue de Abel que chega ao céu... (MENDOZAÁLVAREZ, 2015b, p. 49).

Dessa forma, toca-se no núcleo fundamental para justificar a ontologia relacional, pois não é possível falar de pessoa em relação fora da "abertura como cavidade de sentido", que denota a morte dos justos e inocentes da história fraturada da humanidade, visto que essa "cavidade de sentido originária" define a pessoa em relação (MENDOZA-ÁLVAREZ, 2015b, p. 48-53). Seguindo esta aproximação fenomenológica, é preciso seguir esquadrinhando a "greta do semsentido a partir da experiência das vítimas, para vislumbrar aí a passagem de Deus" (MENDOZA-ÁLVAREZ, 2015a, p. 101). Tratar-se de descrever a transcendência inscrita na imanência do devir intersubjetivo, como redenção em chave de desejo vivido como pura doação no amor assimétrico e gratuito. Essa doação amorosa dos justos e inocentes designará a fonte do sentido, embora não seja o sentido em si, pois este o ultrapassa. Enfim, na perspectiva de uma ontologia relacional da gratuidade e da diferença, o ser divino só pode ser designado como perpétua doação. A vida dos justos e inocentes, de fato, constitui a "pedra de toque da nova temporalidade" própria da subjetividade "declosionada" - expectante e aberta ao vazio - cuja metáfora maior é a boca aberta ou a mão estendida de quem tem fome.

Apesar disso, não se pode esquecer a ambiguidade do desejo humano (MENDOZA-ÁLVAREZ, 2015a, p. 73-74). É exatamente esta ambiguidade do desejo que faz com que o conflituoso espaço intersubjetivo sempre permaneça ancorado na imanência em seu dramatismo violento. Em vista disso, o desvendamento da estrutura mimética da subjetividade com a teoria mimética de René Girard possibilita postular o estágio da subjetividade em chave de desejo como doação. Com Girard descobre-se que a maneira de ser-no-mundo está marcada irreversivelmente pelo mimetismo, de tal maneira que a estrutura 
mimética da subjetividade justifica o paradoxo da condição humana, que se intercala entre violência e redenção, através da invisibilização ou visibilização do outro, do encobrimento ao reconhecimento (MENDOZA-ÁLVAREZ, 2016, p. 3150). A novidade da análise do desejo de René Girard reside na "complexa exterioridade fundante" da subjetividade (MENDOZA-ÁLVAREZ, 2015a, p. 362), isto é, a configuração do desejo se dá pela influência de um terceiro. Esse terceiro se expressa tanto no modelo que se imita, como no próprio objeto desejado. À análise do mecanismo fundante da subjetividade chama-se "teoria do desejo mimético", por meio da qual se compreende a violência intersubjetiva como vontade de onipotência, visto que na mimeses há um potencial aquisitivo. Nisso reside a raiz da violência intersubjetiva que assola a humanidade, desde os primórdios da humanidade. Compreende-se, pois, que o estágio do mútuo reconhecimento, para além da dialética hegeliana como último estágio da subjetividade, passa pelo desvendamento do desejo mimético violento e sua subversão para o desejo mimético de doação.

E esta passagem se faz necessariamente, não pela negação do mimetismo, visto que não é possível deixar de imitar; antes, pela instauração de outro modelo a imitar. Se por um lado a teoria do desejo mimético explica a condição humana mergulhada na rivalidade, por outro lado ela, também, consegue justificar a passagem dessa condição para a condição humana marcada pela oferenda de si mesmo.

Esse outro modelo a imitar foi plenamente revelado em Jesus de Nazaré7, em sua oferenda de si mesmo no seio do contágio mimético. É exatamente essa condição humana reconciliada, marcada pela gratuidade, que o cristianismo dá testemunho para a instauração da Civitas Dei, isto é, a intersubjetividade. Esse estágio advém por meio da superação do ódio e do ressentimento, por uma subjetividade que imita do desejo divino.

\footnotetext{
${ }^{7}$ O Abba de Jesus é o modelo a ser imitado, como fonte do desejo de doação.
} 
O verdadeiro valioso radica no desvelamento de outro tipo de imitação como um processo de reconhecimento do outro que é possível a partir da superação da rivalidade. Tal resolução acontece na história fragmentada e violenta por meio do poder do perdão e da reconciliação. (MENDOZAÁLVAREZ, 2015a, p. 364).

Aquém da carga semântica religiosa e piedosa destes conceitos, a acepção antropológica do "perdão" e da "reconciliação" designa o processo de conversão antropológica. Essa experiência antropológica justifica a existência daquelas pessoas que conseguem fazer a passagem do sacrifício do outro ao sacrifício de si mesmo, nisso reside a verdade de Cristo, a verdade messiânica (MENDOZAÁLVAREZ, 2015a, p. 279).

Nesse horizonte da racionalidade mimética, portanto, messias são todos os justos que conseguem superar a lógica da rivalidade, movendo-se na lógica da gratuidade, como oferenda de si mesmo instaurando a intersubjetividade. Nisto consiste a percepção fundamental do desejo antissacrificial da subjetividade exposta e em doação, pois, a partir dessa realidade antropológica-teologal, instaura-se a nova temporalidade messiânica, abrindo possibilidade de reconciliação e paz no seio da história violenta e conflitiva.

\subsection{Fenomenologia do damné: decolonização da subjetividade}

A proposta de uma ontologia relacional resulta ainda insuficiente para dar conta dos processos de superação do ódio, do ressentimento e da instauração do estágio harmonioso do mútuo reconhecimento para além da dialética hegeliana. $\mathrm{E}$ isso por causa do "esquecimento da colonialidade", que impossibilita de desvendar o racismo epistêmico e ontológico que estrutura a matriz de poder mundial, que se fundou e se perpetua no racismo, isto é, na descartabilidade de uma porção considerável da vida humana (MALDONADO-TORRES, 2008, p. 73). Sem considerar a colonialidade, parece impossível dar uma resposta escatológica ao problema da violência intersubjetiva, bem como seguir pensando uma ontologia relacional e seu correlato a nossa comum humanização. 
Desta forma, parece impossível pensar em processos de nossa comum humanização fora da assunção da fenomenologia do damné, isto é, sem uma ruptura epistemológica que considere o sujeito que nasce da "diferença colonial" sob a construção histórica do negro e da raça. Em tempos de ruptura epistemológica com o pensamento decolonial, Nelson Maldonado-Torres (2007, p. 150) recupera a fenomenologia do damné para dar conta de dizer a "colonialidade do ser" que se operou no interior do sistema/mundo moderno/colonial, que prevalece até os nossos dias em escalada global (MALDONADO-TORRES, 2007, p. 150). A “colonialidade do ser”, segundo este autor, opera na construção do sujeito racial que reduz uma grande parcela da humanidade à sub-ontologia, isto é, à invisibilidade e à subumanidade. O conceito de "colonialidade do ser" se entende melhor à luz da discussão sobre o ego conquiro e do ceticismo misantrópico maniqueu.

Se o ego cogito foi formulado e adquiriu relevância prática sobre as bases do ego conquiro, isto quer dizer que 'penso, logo sou' tem ao menos duas dimensões insuspeitadas. Debaixo do "eu penso" poderíamos ler "outros não pensam", e no interior do "sou" podemos localizar a justificação filosófica para a ideia de que "outros não são" ou estão desprovidos de ser. Desta forma descobrimos uma complexidade não reconhecida da formulação cartesiana: do "eu penso, logo sou" somos levados à noção mais completa, mas também mais precisa, histórica e filosoficamente: “Eu penso (outros não pensam ou não pensam adequadamente), logo sou (outros não são, estão desprovidos de ser, não devem existir ou são dispensáveis)". (MALDONADO-TORRES, 2007, p. 144).

Assim, inicia-se com Descartes a gênesis da colonialidade do ser e do saber, que estão intrinsecamente vinculadas; visto que "o privilégio do conhecimento na modernidade e a negação de faculdades cognitivas nos sujeitos racializados oferecem a base para a negação ontológica” (MALDONADO-TORRES, 2007, p. 145). Mas é com Heidegger que o pensamento decolonial melhor explicita o racismo epistêmico ${ }^{8}$ que conduziu à formulação da "diferença ontológica colonial” ou "diferença sub-ontológica", possibilitando a distinção entre subjetividade humana e a condição de sujeitos sem resistência ontológica.

\footnotetext{
8 “O racismo epistémico descura a capacidade epistémica de certos grupos de pessoas. Pode basear-se na metafísica ou na ontologia, mas os resultados acabam por serem os mesmos: evitar reconhecer os outros como seres inteiramente humanos." (MALDONADOTORRES, 2008, p. 79).
} 
A diferença sub-onto lógica ou diferença ontológica colonial se refere à colonialidade do ser em uma forma similar como a diferença epistêmica colonial se relaciona com a colonialidade do saber. A diferença colonial, de forma geral, é, então, o produto da colonialidade do poder, do saber e do ser. A diferença ontológica colonial é, especificamente, o produto da colonialidade do ser. (MALDONADO-TORRES, 2007, p. 147).

A diferença colonial consiste na classificação de grupos humanos ou populações como exterioridades em relação à interioridade da modernidade. E, desafortunadamente, a diferença colonial, segundo Mignolo, tem raízes no pensamento teológico de Bartolomeu de Las Casa, visto que é o debate sobre o "direito dos povos" que justificará a diferença colonial (MIGNOLO, 2003, p. 95)9.

A diferença colonial é o espaço onde emerge a colonialidade do poder. A diferença colonial é o espaço onde as histórias locais que estão inventando e implementando os projetos globais encontram aquelas histórias locais que os recebem; é o espaço onde os projetos globais são forjados a adaptar-se, integrar-se ou onde são adotados, rejeitados ou ignorados. A diferença colonial é [...] o local ao mesmo tempo físico e imaginário onde atua a colonialidade do poder no confronto de duas espécies de histórias locais visíveis em diferentes espaços e tempos do planeta. (MIGNOLO, 2003, p. 10).

Assim, Mignolo fala de diferença colonial em sua relação epistêmica com a colonialidade do saber. Nelson Maldonado-Torres, por sua vez, a conjuga com a "diferença colonial ontológica", aprofundando assim a ideia de colonialidade do ser. Ambas são, na verdade, dois aspectos da diferença colonial (epistêmico e ontológico), que se relacionam com o poder, isto é, com a exploração, a dominação e o controle (MALDONADO-TORRES, 2007, p. 147).

Ora, a colonialidade do ser, mais especificamente, a diferença colonial epistêmica e ontológica, constitui-se exatamente no processo de negação da imago Dei do sujeito damné, isto é, do sujeito racializado negado em sua humanidade; primeiro a população negra, agora em tempos de capitalismo global a todas as pessoas que não "negadas o direito de ter direito" (MBEMBE, 2018). Trata-se de

\footnotetext{
${ }^{9}$ Mignolo afirma que este debate jurídico-teológico dos "direitos dos povos" do século XVI foi esquecido pela declaração sobre "os direitos do homem e do cidadão" do século XVII. Com isso, o conceito de homem e de cidadão universalizou um tema regional e apagou a questão colonial (MIGNOLO, 2003, p. 95).
} 
uma formulação teórica, com raízes na teologia da cristandade, que reduz a população negra à sub-ontologia, isto é, à subumanidade (MALDONADOTORRES, 2016, p. 82). Em outras palavras, a diferença colonial ontológica nega a humanidade do sujeito racializado, para legitimar a expropriação dos corpos, isto é, ela instaura e perpetua a não ética da guerra por meio da ideia de raça, que implica a violação e assassinato do corpo negro.

A colonialidade é uma ordem de coisas que coloca pessoas de cor sob a observação assassina e violadora de um ego vigilante. $O$ objeto privilegiado da violação é a mulher. Mas os homens de cor também são vistos com estas lentes. Eles são feminizados e se convertem para o ego conquiro em sujeitos fundamentalmente penetráveis. (MALDONADOTORRES, 2007, p. 138).

A colonialidade do ser resulta, portanto, na condenação do damné à uma vida infernal. Diferente do Dasein que está perdido no 'uno' e alcança a autenticidade quando antecipa sua própria morte, o condenado (damné) confronta a realidade de sua finitude e o desejo por sua desaparição como uma aventura diária. A colonialidade do ser faz com que o evento extraordinário de confrontar a mortalidade se converte em um incidente ordinário (MALDONADO-TORRES, 2007, p. 14).

Frantz Fanon - o pensador negro que lutou contra o nazismo na Segunda Guerra Mundial e, mais tarde, contra o imperialismo francês na Argélia -, foi o primeiro a descrever a fenomenologia do damné, em sua obra Os condenados da terra (1968), para falar da condição do negro capturado pelas malhas da colonialidade e os efeitos traumáticos em sua subjetividade. Em sua obra "Pele negra, máscaras brancas" critica o aprisionamento do negro à construção histórica de si mesmo pelo branco, que "rejeita a atualidade e o devir em nome de um passado místico" (FANON, 2008, p. 31). A tarefa que se impõe ao negro é, pois, superar a invenção do negro, isto é, "viver livre da raça e da dominação que carrega o mesmo nome" (MBEMBE, 2018, p. 298). Para isso, há de superar o colonialismo e a escravidão como único referente ôntico na conformação da subjetividade negra (MBEMBE, 2018, p. 263-307). Só então o negro conseguirá superar o ódio e o 
ressentimento e assumir a constitutiva relacionalidade e gratuidade de uma vida em doação. Evidentemente, esse tema nos lança no maior desafio para uma teologia negra, a saber: propugnar uma teologia negra da reconciliação.

Uma coisa parece certa. Se a redenção na intra-história deve acontecer em meio aos processos de mútuo reconhecimento, uma ontologia relacional da gratuidade não pode abstrair-se da fenomenologia do damné, que põe em relevo a emergência de um mundo estruturado sob a base da falta de reconhecimento da maior parte da humanidade como sujeitos doadores, legitimando dinâmicas de possessão e inviabilizando o intercâmbio generoso dos dons.

O damné é, paradoxalmente, invisível e em excesso visível ao mesmo tempo. Este existe na modalidade do não-estar-aí; o que aponta à proximidade da morte ou a sua companhia. O damné é um sujeito concreto, mas é também um conceito transcendental. Emile Benvenise mostrou que o termo damné está relacionado, etimologicamente, com o conceito donner, que significa 'dar'. O damné é, literalmente, o sujeito que não pode dar porque o que ela ou ele tem foi tomado dela ou dele. Isto é, damné se refere à subjetividade enquanto fundamentalmente se caracteriza pelo dar, mas se encontra em condições nas quais não pode dar nada, pois o que tem lhe foi tomado. (MALDONADO-TORRES, 2007, p. 151).

Teologizar a experiência de subjetivação do damné emerge como a tarefa fundamental da teologia negra, em meio à tendência de universalização da condição negra (MBEMBE, 2018); visto que o racismo segue sendo a principal ferramenta que expropria os corpos e forma subjetividades. Uma teologia negra em perspectiva decolonial assume a experiência do sujeito que nasce no mundo marcado pela colonialidade do ser como novo lugar de enunciação e, consequentemente, como novo locus theologicus por excelência da revelação divina, por meio do qual se busca discernir os vestígios da redenção divina na intrahistória humana como um projeto decolonial. 


\section{Considerações finais}

A teologia negra representou para a comunidade negra uma opção decolonial desde o seu nascimento em meados dos anos 1960, visto que ela vem contribuindo para superar a inferioridade que foi introjetada pela diferença colonial. E agora com o retorno visceral do racismo, a teologia não pode prescindir de pensar a "condição negra" que adquire dimensões universais.

Com o pensamento decolonial, a teologia é interpelada a assumir a exterioridade da Modernidade, caso ela não queira ser acusada de cúmplice dos sistemas de exclusão e morte, como o fez a cristandade. Seguir pelo caminho da fenomenologia em vista de uma ontologia relacional da gratuidade parece ser o único caminho possível para pensar em nossa comum humanização, mas sem o esquecimento da colonialidade. Um novo horizonte se abre para a teologia negra, que deve se ocupar dos processos de subjetivação do damné para dar conta da experiência de redenção no coração da história fraturada pelo racismo, que aprisiona negros e brancos.

\section{REFERÊNCIAS}

BURASCHI, D; AGUILAR-IDÁÑEZ, M. Herramientas conceptuales para um antirracismo crítico-transformador. Tabula Rasa, v. 26, p. 171-191, 2017.

CALDEIRA, C. Cristianismo pós-moderno. Midrash do tempo messiânico segundo a teologia de Carlos Mendonza-Álvarez. Theologica Xaveriana, Colombia, v. 187, p. 1-25, 2019.

CALDEIRA, C. Da Europa à América Latina. A vulnerabilidade como locus theologicus. Perspectiva Teológica, Belo Horizonte, v. 50, p. 307-323, 2018a.

CALDEIRA, C. Desconstrução do cristianismo. Imperativo ontológico à experiência de Deus na pós-modernidade. Horizonte, Belo Horizonte, v. 16, p. 1270-1299, 2018b.

CALDEIRA, C. Hermenêutica negra feminista: um ensaio de interpretação de Cântico dos Cânticos 1.5-6. Revista Estudos Feministas, Florianópolis, v. 21, p. 1189-1210, 2013. 
CÉSAIRE, A. Discurso sobre o colonialismo. Lisboa: Augusto Sá da Costa, 2006.

CONE, J. H. O Deus dos oprimidos. São Paulo: Paulinas, 1985.

CONE, J. H.; WILMORE, G. S. Teologia negra. Tradução de Euclides Carneiro da Silva. São Paulo: Paulinas, 1986.

COSTA-BERNARDINO, Joaze; GROSFOGUEL, Ramón. Decolonialidade e perspectiva negra. Revista Sociedade e Estado, Brasília, v. 31, n. 1, p. 15-24, 2016.

DUGGAN, J. Dissonância epistemológica: descolonizando o "cânon" teológico póscolonial. Concilium, Petrópolis, n. 350, p. 10-18, 2013.

DUSSEL, H. 1492, el encubrimiento del otro: hacia el origen del mito de la modernidade. La Paz: Plural Editores, 1994.

DUSSEL, H. Descolonização epistemológica da teologia. Concilium, Petrópolis, v. 350, p. 19-30, 2013.

DUSSEL, H. Transmodernidade e interculturalidade: interpretação a partir da filosofia da libertação. Revista Sociedade e Estado, Brasília, n. 1, p. 51-73, jan./abril. 2016.

DUSSEL, H. Un diálogo con Gianni Vattimo. De la postmodernidad a la transmodernidad. A Parte Rei, n. 54, 2007. Disponível em:

http://serbal.pntic.mec.es/ cmunoz11/dussel54.pdf. Acesso em: 15 set. 2018.

ESTUDOS BÍBLICOS: eu ouvi o clamor do meu povo, Rio de Janeiro, 1988.

ESTUDOS BÍBLICOS: o negro e a Bíblia, um clamor de justiça, Rio de Janeiro, n. 16, 1988.

FANON, F. Os condenados da terra. Rio de Janeiro: Civilização Brasileira, 1968.

FANON, F. Pele negra, máscaras brancas. Salvador: EDUFBA, 2008.

GROSFOGUEL, R. Negros marxistas o marxismos negros? Tabula Rasa, v. 28, p. 11-12, 2018.

HALL, S. Da diáspora: identidades e mediações culturais. Belo Horizonte: UFMG;

Brasília: UNESCO, 2003.

HÉRITIER, F. O eu, o outro e a intolerância. In: BARRET-DUCROCQ (dir.) A

intolerância: foro internacional sobre a intolerância, Unesco, 27 de março de 1997, La Sorbonne, 28 de março de 1997. Rio de Janeiro: Bertrand Brasil, 2000.

KNAUER, P. Ontología relacional. In: QUEZADA DEL RÍO, J. (coord.). Dios clemente y misericordioso: enfoques antropológicos. Homenaje a Barbara Andrade. México:

Universidad Iberoamericana, 2012. p. 19-41. 
MALDONADO-TORRES, N. A topología do Ser e a geopolítica do conhecimento. Modernidade, império e colonialidade. Revista Crítica de Ciências Sociais, v. 80, p. 71-114, mar. 2008.

MALDONADO-TORRES, N. Sobre la colonialidad del ser: contribuiciones al desarrollo de un conpecto. In: CASTRO-GÓMEZ, S; GROSFOGUEL, R (org.). El giro decolonial: reflexones para una diversidad epistémica más allá del capitalismo global. Bogotá: Siglo del Hombre Editores; Universidad Central, Instituto de Estudios Sociales Contemporáneos y Pontifícia Universidad Javeriana, Instituto Pensar, 2007. p.127-167.

MALDONADO-TORRES, N. Transdiciplinaridade e decolonialidade. Revista Sociedade e Estado, Brasília, v. 31, n. 1, p. 75-97, 2016.

MBEMBE, A. Crítica da razão negra. São Paulo: N-1 Edições, 2018.

MELLA, Pablo. La teología latinoamericana y el giro descolonizador. Perspectiva teológica, Belo Horizonte, v. 48, n. 3, p. 439-461, 2016.

MENDOZA ÁLVAREZ, C. Sobre el rebasamiento del cristianismo como totalidad. In: MENDOZA-ÁLVAREZ C. (coord.). La universidad de inspiración cristiana en tiempos de poscristiandad. México: Universidad Iberoamericana, 2007a. p. 41-55.

MENDOZA-ÁLVAREZ, C. De las márgenes al centro vacío. Aportes de la posmodernidad a la teología de la liberación. EATWOT's International Theological Commission, v. 37, n. 4, p. 81-92, 2014.

MENDOZA-ÁLVAREZ, C. Deus ineffabilis. El lenguaje sobre Dios en tiempos de pluralismo. In: DE MORI, G; OLIVEIRA, P. R. de (org.). Deus na sociedade plural: fé, símbolos, narrativas. Belo Horizonte: SOTER: Paulinas, 2013.

MENDOZA-ÁLVAREZ, C. Deus ineffabilis: una teología posmoderna de la revelación del fin de los tempos. Barcelona: Herder: Universidad Iberoamericana, 2015a.

MENDOZA-ÁLVAREZ, C. Deus liberans: la revelación cristiana en diálogo con la modernidad. Los elementos fundacionales de la estética teológica. Fribourg: Éditions Universitaires, 1996.

MENDOZA-ÁLVAREZ, C. Dios es inútil. Por una desconstrucción de las imágenes de Dios. In: HEREDIA J.; ZUBIRÍA G. (coord.). Imágenes de Dios en el mundo contemporâneo. México: UITCAM, 2007b. p. 15-52.

MENDOZA-ÁLVAREZ, C. El Dios escondido de la posmodernidad: deseo, memoria e imaginación escatológica. Ensayo de teología fundamental pós-moderna. Guadalajara: SUJ, 2010.

MENDOZA-ÁLVAREZ, C. La persona en relación como oquedad de sentido. Una aproximación fenomenológica a la cuestión de la dignidad humana. In: MENDOZAÁLVAREZ, C. (comp.). ¿Qué es hoy la dignidad humana? México: Universidad Iberoamericana Ciudad de México, 2015b. p. 39-55. 
MENDOZA-ÁLVAREZ, C. Sobre a invisibilização do outro: uma recepção latino-americana de Levinas e Girard. In: MENDOZA-ÁLVAREZ C.; JOBIM, J. L.; MÉNDEZ-GALLARDO, M. (org.) Mímesis e invisibilização social: a interdividualidade coletiva latinoamericana. São Paulo: É-Realizações, 2016. p. 31-50.

MENDOZA-ÁLVAREZ, C. Teología de la reconciliación en clave mimético-pragmática. In: MENDOZA-ÁLVAREZ, Carlos (coord.) La participación de los cristianos en la construcción del espacio público. México: Universidad Iberoamericana, 2011. p. 199212.

MIGNOLO, W. El pensamiento des-colonial: desprendimento y apertura. Un manifiesto. In: CASTRO-GÓMEZ, S.; GROSFOGUEL, R. (org.). El giro decolonial: reflexones para una diversidad epistémica más allá del capitalismo global. Bogotá: Siglo del Hombre Editores; Universidad Central, Instituto de Estudios Sociales Contemporáneos y Pontifícia Universidad Javeriana, Instituto Pensar, 2007. p. 25-46.

MIGNOLO, W. Histórias locais, projetos globais. Colonialidade, saberes subalternos e pensamento liminar. Belo Horizonte: UFMG, 2003.

NANCY, Jean-Luc. L’adoration. Paris: Galilée, 2010. (Déconstruction du Christianisme, v. 2).

NANCY, Jean-Luc. La déclosion. Paris: Galilée, 2005. (Déconstruction du Christianisme, v. 1).

PADILHA, G. Hermenêutica bíblica negra. In: MENA LÓPEZ, M; NASH, P. T. (org.). Abrindo sulcos: para uma teologia afro-americana e caribenha. São Leopoldo: Sinodal, 2003. p. 110-130.

REVISTA DE INTERPRETAÇÃO BÍBLICA LATINO-AMERICANA: raízes afro-asiáticas no mundo bíblico. Petrópolis, n. 54, 2006.

SILVA, Antônio A. Comunidade negra: 500 anos de resistência. In: ZWETSCH, Roberto (org.). 500 anos de invasão, 500 anos de resistência. São Paulo: Paulinas: CEDI, 1992. p. 179-198.

SPIVAK, G. C. Puede hablar el subalterno? Revista Colombiana de Antropologia. Bogotá, n. 29, p. 297-364, 2003.

SUESS, Paulo. Prolegômenos sobre descolonização e colonialidade da teologia na Igreja: desde um olhar latino-americano. Concilium, Petrópolis, v. 350, p. 78-88, 2013.

VATTIMO, Gianni. Les aventures de la différence. Paris: Éditions de Minut, 1985.

WEST, C. Teologia negra e pensamento marxista. In: CONE, J. H.; WILMORE, G. S. Teologia negra. Tradução de Euclides Carneiro da Silva. São Paulo: Paulinas, 1986. p. 456-475.

ZWETSCH, Roberto (org.). 500 anos de invasão, 500 anos de resistência. São Paulo: Paulinas: CEDI, 1992. 